\title{
Facultad de Música de la UNAM. Notas para un inventario sobre los lugares de la memoria
}

\author{
María-Esther Aguirre-Lora
}

Una sociedad guarda voluntariamente sus recuerdos, los busca y los encuentra. Pierre Nora

\section{RESUMEN}

El año 1929 marca uno de los hitos fundamentales en la vida de la Universidad Nacional Autónoma de México tanto por el logro de la autonomía, patrimonio de todos los universitarios, como por el establecimiento de los estudios musicales universitarios, que directamente competen a la Facultad de Música. Durante las primeras décadas de su existencia tuvieron lugar diversos eventos que la marcaron y contribuyeron a construir la identidad del músico universitario frente al músico conservatoriano. A partir de este horizonte, el propósito de este texto es ofrecer un primer acercamiento a algunas de las huellas sedimentadas en la memoria colectiva de la actual Facultad de Música para explorarlas desde la perspectiva de la dialéctica del recuerdo y el olvido y construir, desde ahí, nuestra memoria histórica.

Palabras clave: músicos universitarios, historia, memoria histórica, memoria/olvido, procesos identitarios, México. 


\section{Faculdade de Música da UNAM. Notas para um inventario sobre os lugares da memoria}

\section{RESUMO}

O ano de 1929 marca um dos símbolos fundamentais na vida da Universidade Nacional Autónoma do México tanto pela conquista da autonomia, patrimônio de todos os universitários, como pelo estabelecimento dos estudos musicais universitários, que diretamente competem à Faculdade de Música. Durante as primeiras décadas de sua existência aconteceram eventos que a marcaram e contribuíram a construir a identidade do músico universitário em comparação ao músico de conservatório. A partir deste horizonte, o propósito deste texto é oferecer uma primeira aproximação a algumas dos rastros sedimentados na memória coletiva da atual Faculdade de Música para explorá-las partindo da perspectiva da dialética da lembrança e do esquecimento e construir, daí nossa memória histórica.

Palavras chave: músicos universitários, história, memória histórica, memoria/esquecimento, processos indenitários, México.

\section{Faculty of Music, UNAM. Notes for an Inventory of Places of Memory}

\section{ABSTRACT}

The year 1929 marked one of the fundamental milestones in the life of the National Autonomous University of Mexico (UNAM), both for the achievement of autonomy, patrimony of all university students, and for the establishment of university musical studies, which directly were entrusted to the Faculty of Music. During the first decades of its existence, several events took place that marked it and contributed to build the identity of the university musician as opposed to the conservatory musician. From this horizon, the purpose of this text is to offer a first approach to some of the traces in the collective memory of the current Faculty of Music to explore them from the perspective of the dialectic of memory and oblivion and to build, from there, our historical memory.

Key words: university musicians, history, historical memory, memory/forgetfulness, identity processes, Mexico. 


\section{Introducción}

El 7 de octubre de 2017 se celebraron los 89 años de existencia de la actual Facultad de Música, lo cual ofrece una excelente ocasión para hurgar más allá del dato fijado como parte de los rituales propios de las celebraciones e incursionar en la memoria, y los olvidos, de una de nuestras instituciones universitarias mexicanas abocadas a la formación artística, específicamente orientada a la profesionalización de los músicos de tradición académica.

Vale decir que la inscripción de una fecha en nuestra memoria universitaria, al repetirse año con año, sin mucha conciencia, oscurece el campo de tensiones políticas y sociales en medio del cual un grupo de estudiantes y de profesores procedentes del antiguo Conservatorio de Música (1866) incidieron en la generación de las condiciones de posibilidad para formar una escuela universitaria de música (1929), alternativa a otras opciones paralelas en relación con el mismo campo profesional.

El propósito de este texto es hurgar en algunas huellas presentes en torno al complejo proceso social a partir del cual se han ido construyendo los "lugares de la memoria", concepto acuñado por el historiador francés Pierre Nora (1884-1992) con reposicionamientos de la clásica "memoria colectiva" planteada por Maurice Halbawchs (1925) en las primeras décadas del siglo $\mathrm{XX}$, desde los cuales la antigua Escuela Nacional de Música de la UNAM habita en nuestra vida cultural en el presente. ${ }^{1}$ Interesa dar cuenta, dialécticamente, de este proceso en el cual emergen tanto los lugares sacralizados como otros tantos disminuidos en su significado, distorsionados o directamente cancelados.

Queda claro que estos lugares no se reducen a objetos materiales; también remiten a espacios imaginarios, a sensibilidades, a percepciones que dan cuenta de lo que pasó, de lo que quedó depositado en algún rincón. Son estos lugares simbólicos, sedimentados en forma de recuerdos en la memoria individual de las personas que forman parte de algunos grupos sociales, reconstruidos en parte a través de la memoria histórica, los que por diversas vías permitieron forjar la identidad de los músicos universitarios frente a los conservatorianos. Pudiéramos decir con Nora (1984: 181) que "se generaron ciertos lugares simbólicos que permitieron dotar de unidad a grupos sociales, que hoy se encuentran vacíos, que son sólo huellas y marcas de memoria perdidas"; son estos lugares portadores de significado que, a la manera de los semiósforos propuestos por Pomian (1999), constituyen algunas de las señales, de los signos propicios para develar sustratos que permitan ampliar el horizonte de comprensión de la actual Facultad de Música de la UNAM, donde historia, memoria y procesos identitarios converjan en la apuesta de futuro que el día con día construye en la formación artística universitaria.

Lo que aquí presento ha implicado el recorrido obligado, por una parte, por el Archivo Histórico de la UNAM (AHUNAM), el Archivo Vertical de la Escuela Nacional de Música y la Hemeroteca Nacional, en busca de fotografías, documentos de declaración de principios, programas de aniversarios y otros festejos, así como de algunos escritos hechos ex profeso para conservar el recuerdo de los acontecimientos vinculados con la fundación de la Escuela; por otra, ha requerido seguir otros rastros en la propia cultura material de la Facultad. Por último, otra fuente obligada, han sido los informantes calificados que aporten pistas en relación con nuestro propósito. $^{2}$

\footnotetext{
${ }^{1}$ Una versión inicial de este texto se presentó en el Simposio internacional La memoria escolar. Nuevas tendencias en la investigación histórico-educativa: perspectivas heurísticas y cuestiones metodológicas (Sevilla, septiembre 22 al 25 del 2015).

${ }^{2}$ Algunos de los principales estudios e indagaciones que se han hecho sobre la historia de la actual Facultad de Música se mencionan a lo largo del escrito, partiendo de Alba Herrera y Ogazón, Estanislao Mejía, Jesús C. Romero, hasta llegar a Betty Zanolli y María Esther Aguirre Lora.
} 
Organizo el texto en tres ejes: 1. El evento; 2.Hurgar en los lugares de la memoria; 3. Fragilidad de la memoria.

\section{El evento}

Antecedido por diversas iniciativas, en 1866, durante el breve imperio de Maximiliano de Habsburgo, se fundó el Conservatorio de Música, institución consagrada a la formación de instrumentistas, cantantes y compositores, que en el curso de su larga historia se fue adecuando a los cambios políticos y culturales de la sociedad mexicana, ${ }^{3}$ sin perder su lugar de privilegio en el campo de la música erudita. Algunas de las principales transformaciones y crisis que experimentó durante las primeras décadas del siglo XX, en consonancia con los programas modernizadores de las instituciones mexicanas, y que aportan material de estudio para rastrear los 'lugares de la memoria', fueron:

1. Transitar de ser una institución particular surgida por la iniciativa de un grupo de melómanos (Club-Sociedad Filarmónica Mexicana, 1866) a erigirse en la institución pública por excelencia, regulada y financiada por la Secretaría de Instrucción Pública y Bellas Artes (1905), en la que se delegó la profesionalización del músico artista.

2. En el contexto de la reestructuración de secretarías y dependencias del Estado mexicano, con la disolución de la Secretaría de Instrucción Pública y Bellas Artes (1905-1917), pasó a depender del recién creado Departamento Universitario y de las Bellas Artes, lo cual implicó participar de las normas y prácticas del régimen universitario y no del sistema de instrucción pública que se estaba reconstituyendo (1924) (Zanolli, 1997, v. 1: 363).

3. A raíz de los debates que se dieron en el contexto de los dos Congresos Nacionales de Música (1926-1928), de algunos de los acuerdos de reformas que derivaron de ello (Aguirre, 2016) y de la dirección que asumiera el reconocido músico Carlos Chávez (1899-1978), el Conservatorio entró de lleno a modificar sus programas, sus prácticas, su mismo nombre: de entonces en adelante sería Escuela de Música, Teatro y Danza (1928-1929), aunque esto no se mantuvo por mucho tiempo por protestas de los propios conservatorianos, que no se reconocieron en la amalgama de campos artísticos (Aguirre, 2008, 2015).

Entre los cambios decisivos que se plantearon en esta fase se encuentra la separación del Conservatorio de la Universidad Nacional de México y su reintegración a la Secretaría de Educación Pública. Esto desencadenó, a finales de 1928, la franca inconformidad de un grupo de profesores y alumnos, ${ }^{4}$ que expresaron en distintos foros y formas disgusto por su segregación del ámbito universitario. En la medida en que creció la inconformidad, profesores y alumnos llegaron a situaciones extremas, como oponerse directamente a regresar al Conservatorio, cancelando todo vínculo con la institución. La única solución viable, y fue por la que apostó el grupo disidente, cristalizó en la creación de lo que podría ser un 'conservatorio universitario', y a ello dirigieron todas las

\footnotetext{
${ }^{3}$ Indicio de la sucesiva transformación de sus funciones y de las tramas de las políticas culturales en que iba quedando inmerso fueron sus diferentes denominaciones: Conservatorio de Música y de Declamación de la Sociedad Filarmónica Mexicana (1869), Conservatorio Nacional de Música y de Declamación (1877), Conservatorio Nacional de Música (1883), nuevamente Conservatorio Nacional de Música y de Declamación (1900), Escuela Nacional de Música (1917-1918), Escuela Nacional de Música y Arte Teatral (1920), Conservatorio Nacional de Música (1922), Escuela Nacional de Música, Teatro y Danza (1928-1929). Sólo hasta 1929 recuperará una de sus denominaciones iniciales: Conservatorio Nacional de Música (Zanolli, 1997).

${ }^{4}$ Me refiero a Alba Herrera y Ogazón, Estanislao Mejía, Consuelo Escobar de Castro, Ana María Charles, José Rocabruna y Carlos Castro.
} 
presiones, alianzas y búsqueda de relaciones que les fue posible: pronunciamientos en los principales diarios del país, ante los órganos de gobierno universitario y en la presidencia de la República, participación en movimientos estudiantiles, y otras más.

En medio de la efervescencia del clima político, si tomamos en cuenta la complejidad de las circunstancias nacionales de un país que transitaba hacia la modernización económica ${ }^{5}$ y el clima internacional propio de las tensiones que se manifestaban entre los que serían las dos guerras mundiales, así como la emergencia de la gran depresión, el evento se cruzó con otro de gran envergadura: la lucha por el logro de la autonomía universitaria (1929), precedida por una huelga estudiantil de dimensiones hasta entonces desconocidas, y con él se cobijó. Las autoridades estaban renuentes a establecer estudios musicales universitarios; ya se había aprobado el proyecto propuesto por Carlos Chávez (1899-1978), con el pleno convencimiento de que sólo en el marco de las políticas públicas y el financiamiento del Estado podría progresar una institución como ésta, pero sucedió lo insólito: en la efervescencia del movimiento por la autonomía y la movilización estudiantil, la opinión pública dio un viraje de ciento ochenta grados. En la sesión del Consejo Universitario del 7 de agosto de 1929, presidida por el rector Ignacio García Téllez (1897-1985), se aprobó, por unanimidad, la creación de la Facultad de Música (a escasos años redefinida como Escuela Superior de Música, y en años recientes restablecida como Facultad) $)^{6}$ y se nombró la comisión que concretaría esta iniciativa, inaugurando los cursos en los espacios que quedaban desocupados en la Facultad de Filosofia y Letras (edificio Mascarones) una vez cubiertos sus propios horarios de clase, después de sortear varias dificultades, el 7 de octubre de 1929.
Ahora bien, ¿cómo es que estos eventos comenzaron a tomar forma en el imaginario colectivo y cómo devinieron memoria histórica? ¿A qué representaciones dio lugar la empresa de establecer un conservatorio universitario de música? ¿Cómo fue posible la convergencia de múltiples memorias individuales, plurales en su heterogeneidad, para crear lazos de solidaridad entre el grupo que luchaba por fundar estudios musicales universitarios?

\section{Hurgar los lugares de la memoria}

La empresa asumida no fue fácil: el establecimiento de la Facultad de Música, cuya apuesta por 'ser diferentes', por ser músicos universitarios, por llegar a obtener el grado de Doctor en Música, exigiría la constante definición de la propia identidad, de las propias prácticas, la afirmación de la audacia y el riesgo de las propias decisiones, el fortalecimiento del sentido de pertenencia a una comunidad universitaria, tareas en las que mediarían los encuentros y desencuentros, las coincidencias y divergencias con otras instituciones afines, que habitaban las tramas de la vida social y cultural de México. Ello implicaba la creación-recreación de un pasado común, el encontrar los puntos de convergencia, la evocación pública de los lazos fraternales donde se compartiera un proyecto omitiendo las divergencias, el proceso de reconocer, y aun de inventar, los lugares mediante los cuales podemos decir, parafraseando a Pierre Nora, "una sociedad guarda voluntariamente sus recuerdos, los busca y los encuentra" (Araujo y Quijano, 2011: 177).

¿Qué indicios podemos identificar en la construcción de la memoria colectiva de la Facultad de Música? ¿Cuáles son los recuerdos e historias sedimentadas a lo largo de los años a partir de las cuales podríamos replantear nuestra comprensión histórica

\footnotetext{
${ }^{5}$ Los ambientes estaban convulsionados por el asesinato de Álvaro Obregón en 1928, reelecto para un segundo periodo presidencial, la primera sublevación de los Cristeros (1926-1929), el establecimiento del Partido Revolucionario Institucional, entre otros eventos de gran complejidad.

${ }^{6}$ AHUNAM [IISUE], Fondo Escuela Nacional de Música, primera remesa, exp. 140, ff 1-5, ff 10-12, 14.
} 
de la institución, de la actuación de sus protagonistas, de su sentido social?

\section{Himnos y corridos en la convivencia cotidiana}

Se trata de dos géneros musicales, de antigua tradición, que fueron paradigmáticos por aquellos años 30 , presentes en la sociedad en general, en el establecimiento de nuevas instituciones, en la vida universitaria, entre los músicos que recién se reincorporaban a la Universidad de México.

La convivencia estudiantil, facilitada en la cercanía que propiciaba el Barrio Universitario en el centro de la ciudad de México, se fortaleció al calor del movimiento que luchaba por la autonomía universitaria, entramado en la fundación de un conservatorio universitario (Díaz y de Ovando, 1979; Díaz Arciniega, 1989). En medio de las reuniones y convivencia cotidiana de estudiantes y profesores para intercambiar puntos de vista, estudiar, informarse de las novedades, llegar a acuerdos con las autoridades, surgieron al menos dos composiciones que se conservan en los archivos universitarios: el "Corrido de la huelga", con música del Corrido de "La cárcel de Cananea", ${ }^{7}$ en el que se hace un recuento de los acontecimientos que tuvieron lugar alrededor del movimiento de autonomía protagonizado por los estudiantes. Esta composición nos introduce en facetas de la vida cotidiana de estas luchas, tales como las gigantescas marchas que se llevaron a cabo en la ciudad de México - los diarios reportaban entre diez mil y veinticinco mil estudiantes - demandando la renuncia del rector, de otras autoridades universitarias y aun de los funcionarios del gobierno. Pero, en medio de las protestas, las muestras de simpatía y solidaridad con los estudiantes no se hacían esperar: a su paso caían laureles y claveles rojos y el clamor de las ovaciones crecía mezclándose con otras canciones entonadas por los estudiantes, algunas del dominio público, otras compuestas por ellos. No cabe duda que el corrido, como género, resultaba adecuado para que los estudiantes narraran su propia épica en el movimiento de autonomía universitaria. Para muchos de los estudiantes la revolución y sus cantos constituían un recuerdo de infancia, una tradición heredada desde muy antigua data y revitalizada en los años recientes con el movimiento revolucionario de 1910. Cantar el "Corrido de la Huelga" era dar forma a sus propias hazañas, hacer un recuento de las audacias de sus "muchachos valientes" (sic.) y resguardarlas, como un valioso recurso de cohesión del grupo universitario frente a lo que consideraban su lucha histórica.

El otro tipo de composición literario-musical vinculado al evento de la fundación, fue el "Himno a la Huelga pro Facultad de Música”, este último compuesto por estudiantes del ex Consejo General de Huelga en la víspera de la sesión de Consejo Universitario que aprobó el establecimiento de estudios musicales universitarios a la que aludíamos, si bien su estreno estuvo a cargo de la orquesta de la Facultad de Música, en el segundo aniversario de la inauguración de los estudios (1931), ${ }^{8}$ después de que mediaran los certámenes convocados por el rector, Ignacio García Téllez, y el director de la nueva institución, Estanislao Mejía, convencidos de la necesidad de que esta Universidad, renovada con el proyecto de autonomía, tuviera su propio himno (Aguirre, 2016, 2017).

\footnotetext{
${ }^{7}$ Se publicó en La Huelga, órgano de los estudiantes de la Facultad de Derecho y Ciencias Sociales, núm. 6, 5 de junio de 1929. Eran pliegos de 73 por $93 \mathrm{~cm}$. que, a manera de tableros informativos, se pegaban en los postes y en las esquinas más concurridas, con el propósito de difundir las noticias del movimiento estudiantil.

${ }^{8}$ Para profundizar al respecto puede consultarse Aldo Mier, Yolopatli Rosas, Laura Servín, 2008: 345-374.
} 


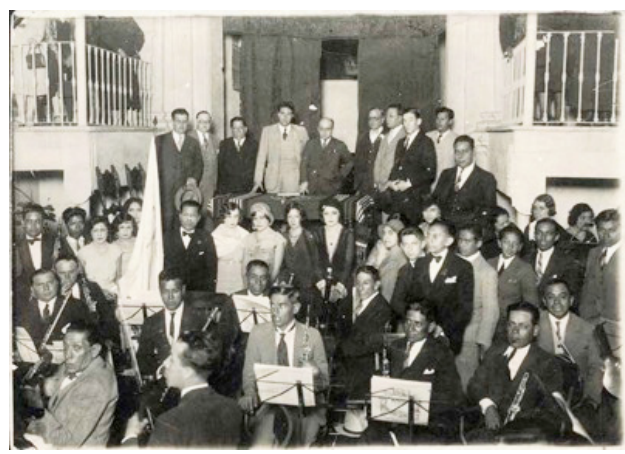

Fuente: Archivo Vertical de la Facultad de Música de la UNAM.

Todo ello fortalecía los lazos en el grupo de músicos disidentes del Conservatorio y los líderes estudiantiles que se habían comprometido, con uno de los acuerdos derivados del Consejo General de Huelga, a apoyar la creación de un centro de estudios musicales en la Universidad. ${ }^{9}$ Se trataba de lenguajes, en el más amplio significado del término, que incidían directamente en el sentido de cohesión y de identidad de las sociedades donde habría de construirse el nosotros weberiano.

\section{Narrar las heroicidades de los orígenes}

Para el primer aniversario de la fundación de la Facultad de Música (1930), la primera academia mixta de profesores y alumnos estableció como una de sus tareas más urgentes dar cuenta de lo que había sucedido, de cómo se había fundado la Facultad antes de que cayera en el olvido. La preocupación por dejar constancia de lo vivido, por narrar a quienes vinieran después, por no olvidar los orígenes como forma de asegurar las decisiones del presente y recordar a los otros la apuesta de un grupo de músicos disidentes que se dispusieron a dar forma a sus propias opciones universitarias, cristalizó en la primera historia de la Facultad de Música, realizada por Alba Herrera y Ogazón (1885-1931), profesora de piano y de historia de la música, y María Caso (1895-?), profesora de francés, ambas parte del grupo de los disidentes conservatorianos, fundadores de la Facultad de Música. ${ }^{10}$ Pasaron muchos años para que hubiera nuevamente la voluntad explícita de escribir la historia de la Escuela; siempre que había necesidad se recurría de nueva cuenta a la escrita por Alba Herrera y María Caso. Para 1947, el director en turno, maestro Luis G. Saloma, la encomendó al maestro Estanislao Mejía (1882-1967); ${ }^{11}$ también el músico e historiador Jesús C. Romero (1883-1958) la escribió por iniciativa personal (1947).

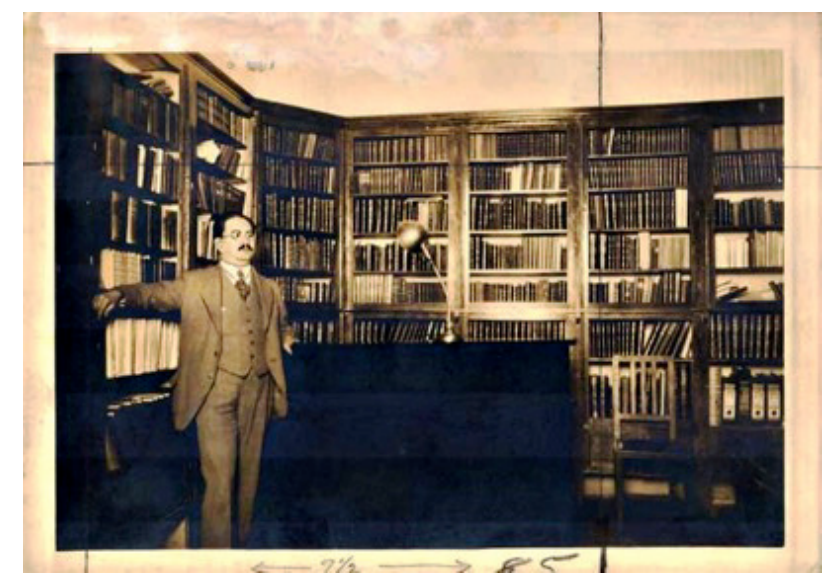

Jesús C. Romero. Fuente: Archivo Vertical de la Facultad de Música de la UNAM.

\footnotetext{
${ }^{9}$ A mediados de 1929 se logró resolver el movimiento cristero, que databa de 1926; en octubre de 1929, el centro antirreeleccionista lanzó la candidatura de Vasconcelos. Los resultados de las primeras elecciones de esta naturaleza se darían en el mes de noviembre. De los grupos de jóvenes universitarios, unos se abocaron al vasconcelismo en tanto que otros se concentraron en el movimiento por la autonomía universitaria.

${ }^{10}$ AHUNAM, Fondo Escuela Nacional de Música, primera remesa, "Breve historia de la fundación de la Facultad de Música por las profesoras señoritas Alba Herrera y Ogazón y María Caso" [1929], caja 14, exp. 5, pp. 4928-4945.

${ }^{11}$ Mejía, 1947. Se trata de un volumen de 591 páginas en el cual, en el contexto del desarrollo del Arte de la Música en nuestro país, de finales de la Revolución hasta la década de los cincuenta, el autor da cuenta de los orígenes de la Escuela Nacional de Música de la UNAM. Fruto de materiales reunidos a lo largo de sus 19 años de trabajo profesional, integra, transcribiéndolos, documentos, artículos y noticias fundamentales para ambas historias, la de la ENM y la de la Música en México.
} 


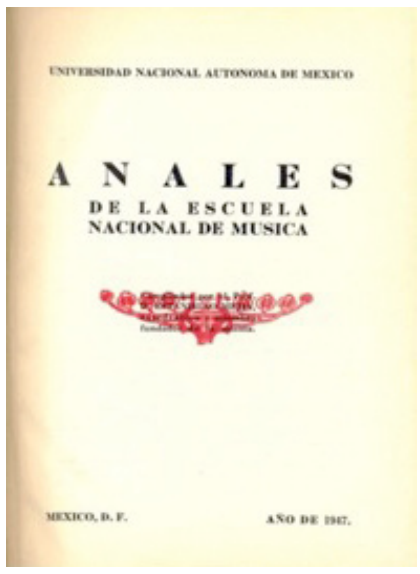

Estanislao Mejá. Fuente: Anales de la Escuela Nacional de Música, México, 1947.

Son historias escritas en primera persona, por quienes protagonizaron los acontecimientos, filtradas, en mayor o menor medida, por la emoción del momento y el fervor de la apuesta; vistas desde dentro, desde el ángulo de los músicos que decidieron seguir siendo universitarios. Predominan las historias triunfalistas, llenas de heroicidades, marcadas por la condición epopéyica del momento, cuyo registro, en una perspectiva cronológica, de tiempo lineal, ordena los acontecimientos que requieren ser recordados, que ni los músicos universitarios ni las comunidades artísticas más amplias deberían olvidar... También hay historias, como la de Jesús C. Romero y aun la de Estanislao Mejía, hechas con más conocimiento del 'oficio', con manejo de fuentes documentales y orientadas hacia la comprensión de la fundación de la Escuela de Música en la Universidad.

Pero también hay memoria de lo que sucedió en otros documentos, como las cartas aclaratorias o los informes de actividades de los directores, que integran los consabidos 'antecedentes', solicitados por las autoridades universitarias u otras instancias, que a la vez servían de punto de comparación para medir los logros frente a la fragilidad y provisionalidad que inicialmente se le atribuyeran a la nueva institución. Todo ello sustentado en una cuidadosa elección de los datos, se erige en otros tantos escritos memorativos abocados a decir quiénes son los músicos universitarios, de dónde y cómo surgen. Era persistente la necesidad de explicitar y justificar su presencia en la institución universitaria y distanciarse del Conservatorio.

\section{Conmemoraciones}

El proceso identitario de los músicos universitarios fue un largo camino por recorrer y dar forma a su propio rostro - expresión de múltiples rostros como dependencia universitaria dirigida a la formación musical del país, que se quería del más alto nivel; implicó para la comunidad académica retos recurrentes, posturas y reflexiones que atravesaban distintos planos de la arquitectura que se quería construir y que fueron expresadas en las distintas conmemoraciones de aniversarios ${ }^{12}$ homenajes y reconocimientos, balances, audiciones escolares y ceremonias públicas, convocatorias para las inscripciones, debates en algunas acaloradas sesiones de Consejo Universitario eran ocasiones propicias para expresar un punto de vista.

En estos contextos y ocasiones, un motivo recurrente era el ideal de la profesionalización del músico universitario, la dificultad de las soluciones para el necesario tránsito del ejercicio, limitado, del oficio centrado en la habilitación técnica, al fortalecimiento del conocimiento, amplio e integral, del campo de lo musical, pero, por otro lado, cuál podría ser su papel en la consigna de educar a las masas, que dominaba las políticas culturales de los gobiernos revolucionarios. También estaba presente la preocupación por lo que se percibía como pobreza de los ambientes musicales, situación que la joven comunidad de músicos universitarios se proponía superar.

\footnotetext{
${ }^{12}$ Archivo Vertical, Facultad de Música, UNAM, Fotografía de Primer aniversario de la fundación, Aniversario de la fundación, Banquete aniversario fundación, 1941, Foto y programa Aniversario 1943.
} 


\section{Nombrar instituciones}

Desde su origen, y también como una de las prácticas aprendidas en el Conservatorio Nacional de Música, la Escuela Nacional de Música impulsó la Orquesta Sinfónica de la Facultad de Música (1929), y con ese nombre se mantuvo hasta años recientes (2015), en que se renombró Orquesta Sinfónica de la Facultad de Música "Estanislao Mejía".

¿Cómo explicar este reconocimiento a quien fuera el primer director de la ex Facultad de Música? Media al respecto la investigación hecha por Heriberto Acuña Palacios, músico tlaxcalteca, quien desde 1993 se dio a la tarea de indagar en acervos de la hoy Facultad de Música, del Conservatorio Nacional de Música, del Centro Nacional de Investigación, Documentación e Información Musical Carlos Chávez (CENIDIM), del Archivo Histórico de la UNAM, e incluso en archivos personales y testimonios de amigos, conocidos y familiares del maestro Mejía, la vida y las composiciones de Estanislao, presentarlas en distintos foros logrando el reconocimiento de sus aportaciones y del papel que jugó en la fundación de los estudios musicales universitarios. ${ }^{13}$ La propia institución universitaria fue cobrando conciencia de los protagonistas que lucharon por el sentido del naciente proyecto.

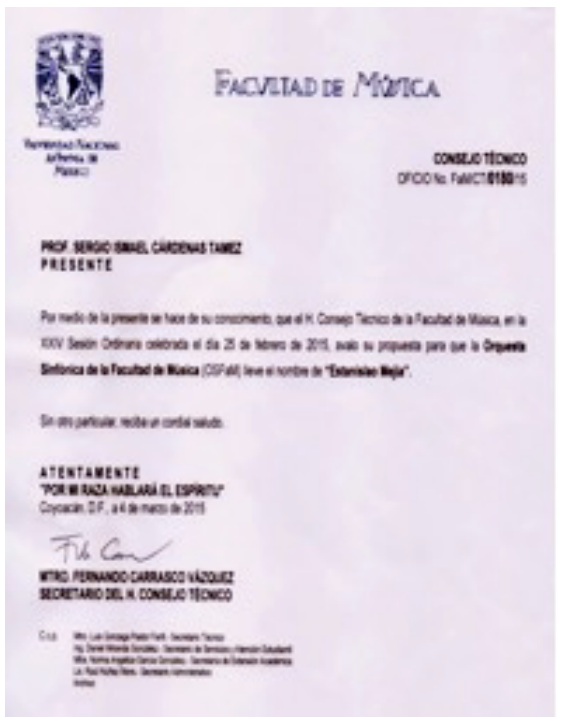

Documento emitido por el Consejo Técnico de la Facultad de Música de la unam en el que se autoriza el cambio de denominación de la Orquesta Sinfónica de la Facultad. Fuente: Archivo de la Secretaría General de la Facultad de Música, UNAM.

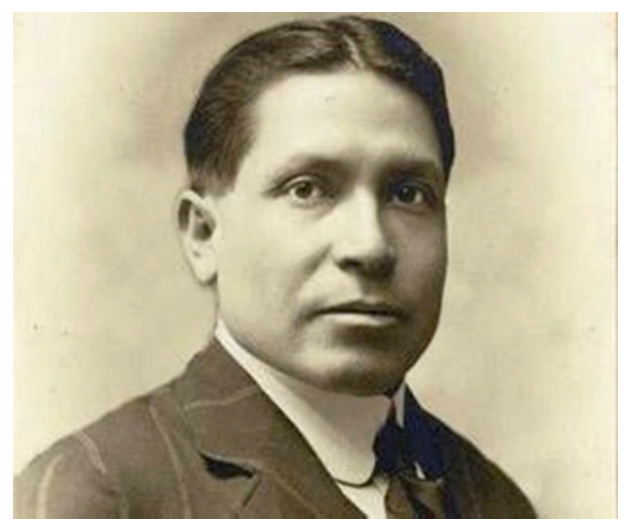

Estanislao Mejía Castro. Fuente: AHUNAM [IISUE].

Otras huellas de la memoria que han reconstruido los músicos podemos apreciarlas en el nombre que han dado a algunos salones de la Facultad (Xicoténcatl 126, Coyoacán, Ciudad de México). Se trata de nombres de académicos que han tenido un papel protagónico en la vida de la institución, como son María Bonilla (1892-1990), primera directora, que quedó borrado en algún remozamiento del edificio. También es cierto que un recorrido por las aulas da cuenta de los nombres que remiten a profesores que en algún momento de la Escuela dieron clases y obtuvieron el reconocimiento de sus alumnos y colegas. Prevalece como criterio colocar una placa afuera del aula donde el profesor daba clases; las iniciativas han tenido distintas procedencias, pero en su mayoría no ofrecen información relevante sobre las aportaciones del protagonista, ni los mínimos datos biográficos. Alguna asemeja una inscripción lapidaria donde el lamento por la pérdida está presente:

\footnotetext{
${ }^{13}$ Por su parte, la Escuela de Música del Estado de Tlaxcala lo reconoció, poniéndole su nombre a su Sala de conciertos (2017).
} 


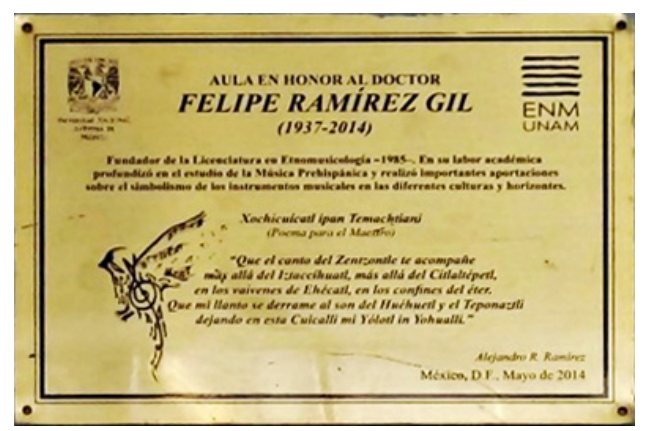

En el caso de Manuel M. Ponce (1882-1948) reconocido músico, compositor y maestro de varias generaciones, cuya obra quedó inscrita en el programa Registro Memoria del Mundo de México, de la Organización de las Naciones Unidas para la Educación, la Ciencia y la Cultura (("Declaratoria...", 2010), ${ }^{14}$ más allá de los numerosas muestras de reconocimiento a su trabajo que se han dado particularmente en Zacatecas y Aguascalientes, sus lugares de procedencia, ${ }^{15}$ la Escuela de Música de la UNAM, en donde fue director por un corto periodo (1945-1948), le consagró una placa de agradecimiento junto con la paulatina publicación de su obra a partir del proyecto editorial coordinado por Paolo Mello, profesor en la misma Facultad de Música:

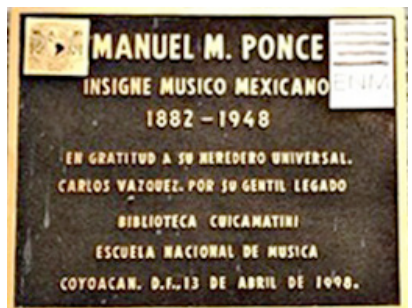

Placa en reconocimiento a Manuel M. Ponce. Sala de lectura de la Biblioteca Cuicamatini de la Facultad de Música de la UNAM.

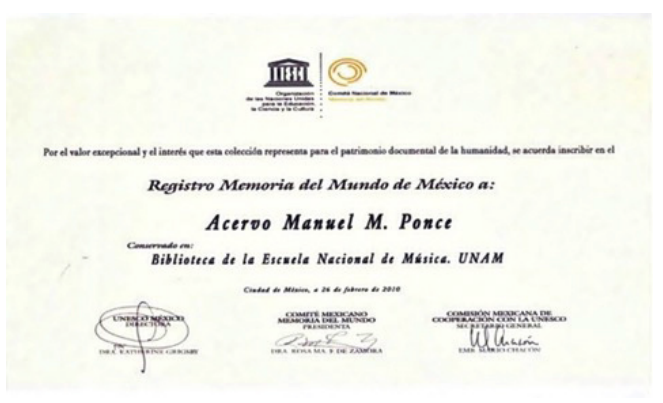

Registro de la obra de Manuel M. Ponce en la Biblioteca de la Facultad de Música de la unam (UNESCO, 2010).

Una placa conmemorativa más, que ocupa un lugar central en la misma sala de lectura de la Biblioteca Cuicamatini, es la dedicada al Maestro Luis G. Saloma (1866-1956), uno de los más importantes directores de la Escuela Nacional de Música de la UNAM y formador de violinistas del más alto nivel. La placa no tiene fecha y resulta una interesante rectificación de la primera placa, anodina, que quedó afuera de algún salón de clase, lo cual es indicio de la mayor conciencia de la institución con respecto a su historia.

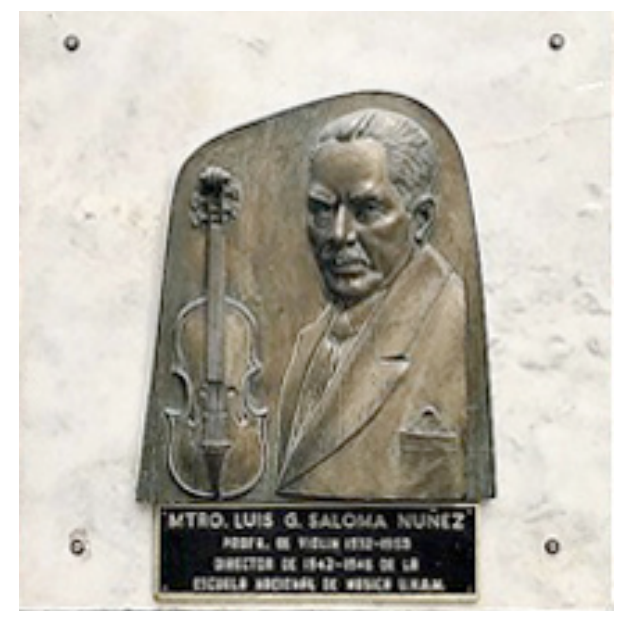

\footnotetext{
${ }^{14}$ Fue entonces cuando cristalizó la iniciativa que un grupo de intelectuales y artistas había planteado desde 1992 con el propósito de resguardar su obra como parte del patrimonio de la humanidad. Se trata de un promedio de 550 obras que se conservan en la Biblioteca de la Facultad de Música, donadas por el maestro Carlos Vázquez, de la propia Escuela Nacional de Música, quien fue heredero de la obra y los bienes de Ponce. Vid. "La colección Manuel M. Ponce ya es parte del programa Memoria del Mundo de México 2010", "Declaratoria de la UNESCO" (2010), Boletín, núm. 375, México, UNAM-Dirección General de Comunicación Social, junio [http:// www.dgcs.unam.mx]..

${ }^{15}$ En años recientes, 2014, CONAGULTA inauguró en Zacatecas el Museo Manuel M. Ponce que alberga su piano, varios objetos personales y alrededor de 4000 documentos. También, a partir de ese año, se estableció el Festival Musical Manuel M. Ponce. Existen esculturas conmemorativas tanto en la Alameda de Zacatecas como en la Plaza de la Patria de Aguascalientes; su cuerpo fue trasladado a la Rotonda de los Hombres Ilustres (ciudad de México, 1952), sólo por mencionar algunas. Manuel M. Ponce es originario de Fresnillo, Zacatecas, y vivió un tiempo en Aguascalientes, antes de iniciar sus estudios en la ciudad de México (1900).
} 


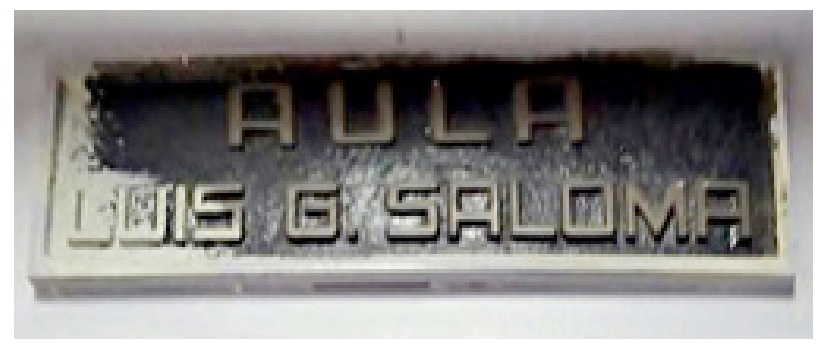

\section{En la fragilidad de la memoria}

Pero, más allá de las heroicidades, las conmemoraciones, los sueños realizados, las actas del Consejo Universitario, la prensa, los testimonios, también develan lo que no se dice, lo que se quiere olvidar, lo que simplemente se ignora. Son los fantasmas de la memoria con los que los músicos universitarios han tenido que luchar, sobre los que habrían de seguir construyendo.

A los pocos años de fundada la Facultad de Música, su estatus de Facultad y su propia existencia en el ámbito universitario fueron duramente cuestionados en el pleno del Consejo Universitario; ${ }^{16}$ en la medida en que parte de su población, obedeciendo a la necesidad de aproximarse al campo musical desde muy tempranas edades, la constituían (y la constituyen) niños y jovencitos, herencia del modelo de los antiguos conservatorios, que ha constituido un eje importante de la vida de la Facultad. También su pretensión de otorgar el grado de doctor en música, conforme a la imagen de la antigua universidad novohispana, se invalidó por carecer de personal idóneo para ello. Pocos meses después, en el estatus universitario, pasó de Facultad a Escuela Superior de Música. ${ }^{17}$ Será hasta el año 2014 cuando se cierra el círculo y nuevamente adquiere el rango de Facultad.
Más tarde, en vísperas de la huelga universitaria de 1933, en relación con los rumores sobre su posible desaparición, los músicos universitarios darían la batalla por el lugar de las escuelas de arte en la Universidad, de matriz positivista y prioritariamente abocada en ese entonces a la formación de profesiones liberales - médicos, abogados, ingenieros, arquitectos, filósofos, literatos, historiadores, entre otros (Arce et al., 1982).

Asimismo, el peso del Conservatorio y el lugar que ocupaba en el imaginario social marcó la vida de la naciente Facultad en su necesidad de legitimarse frente a la que siguió siendo la institución matriz, tradicionalmente abocada a la formación musical, ya en estrecha relación con los proyectos del Estado (Conservatorio Nacional de Música) y que había recibido, por lo demás, el impulso renovador de Carlos Chávez. Todo esto debilitaba el sentido de pertenencia a la institución.

Por otra parte, hasta años recientes persistió una actitud de franco rechazo hacia Carlos Chávez por interpretaciones sesgadas sobre las declaraciones que hizo en su momento (1929) al defender su visionaria propuesta sobre la formación de los músicos: "México no necesita doctores ni bachilleres en música $[\ldots]$ necesita buenos ejecutantes de banda, de orquesta, de ópera y de ballet, etcétera, así como profesores de instrucción musical media" (Chávez, 1929). Puede decirse que hasta años recientes se conservó como distanciamiento de ambos proyectos, el de los músicos conservatorianos y el de los músicos universitarios, sin entender el fondo de la propuesta: Chávez partía de las distintas atribuciones de ambas instituciones. El Conservatorio habría de empezar

\footnotetext{
${ }^{16}$ El director, Estanislao Mejía, dirigía un oficio al Secretario General en el que señalaba: "La modificación substancial radica en haber eliminado las materias de la secundaria, que existían en el plan de estudios de 1932, de acuerdo con las instrucciones verbales que se sirvió usted hacer a esta Dirección, para no infringir así los reglamentos respectivos". Archivo Histórico del Consejo Universitario, UNAM, exp. 6, año 1933, p. 116.

${ }^{17}$ Versión taquigráfica de la Sesión Extraordinaria del H. Consejo Universitario efectuada el día 23 de marzo de 1933 (Archivo Histórico del Consejo Universitario, UNAM, exp. 6, año 1933, p. 76 y ss). En la misma sesión el rector nombró una comisión integrada por Ignacio Chávez, Enrique O. Aragón y Roberto Mantilla, consejeros por Música y Filosofía respectivamente, y por Enríquez, Carvajal, Martínez Mezquida, Haro Tamariz, consejeros por Música, para que determinara lo que debería entenderse por facultad universitaria y por escuela universitaria para fundamentar el caso de Música (Aguirre, 2016: 106).
} 
por formar músicos desde abajo: de banda, orquesta, etc., y una vez cubierto esto, y si ese fuere el caso, proceder a impulsar la alta cultura musical, incluso universitaria (loc. cit.). Abogaba por una instancia que coordinara las instituciones abocadas al arte, y no como sucedería en la Universidad, que habría de coexistir con la formación de profesionistas de muy diversas áreas; el otro grupo, encabezado por Estanislao Mejía, uno de los representantes de la disidencia conservatoriana y primer director de la Facultad de Música, se remitía a uno de los acuerdos del Primer Congreso Nacional de Música que planteaba elevar los estudios musicales al nivel de educación superior, y aun otorgar el grado de doctor en música, conforme a la práctica de la antigua Universidad. ${ }^{18}$

Por lo demás, la Escuela de Música, en el curso de varios años, mantuvo la necesidad de legitimarse tanto a nivel de la propia Universidad como frente al Conservatorio. La amenaza de su desaparición, la duplicidad de funciones con respecto a la oferta del Conservatorio era la espada de Damocles sobre la cabeza de la comunidad de músicos universitarios, quienes enfrentaban optimistamente las objeciones de su pertinencia como institución formadora, argumentando la "noble competencia", propicia a la superación de la propia institución. 1949, año de la inauguración del edificio del Conservatorio en Presidente Masaryk 582, desencadenó de nuevo las objeciones referidas a la existencia de la Escuela de Música, en la medida en que en el periódico se comparaban las posibilidades y recursos de la Escuela de Música frente al Conservatorio:

El doctorado en Música supone la más alta formación cultural y su creación vendría a estimular muy hondamente a los estudiantes de la materia frente a la perspectiva de poseer un galardón profesional capaz de equipararse, y aun superar, a otros que expide la Universidad. Precisa y únicamente UNA UNIVERSIDAD ES CAPAZ DE OTORGAR DOCTORADOS Y ANTE LA INÚTIL Y ESTÉRIL DUPLICACIÓN DE LA ESCUELA UNIVERSITARIA DE MÚSICA y la carencia de un Instituto de Música exigiblemente universitario, nosotros argumentamos: ¿Por qué no se evita la primera y se crea el segundo para el beneficio del progreso musical de la Patria?. ${ }^{19}$

Ahora bien, una vez establecida la nueva escuela universitaria de música para iniciar las clases, el 7 de octubre de 1929, faltaban, ni más ni menos, los instrumentos musicales para estudiar, situación que no tardaría en divulgarse a través de la prensa capitalina: se cuenta con un "magnífico local, un magnífico profesorado y alumnos inscritos pero no se cuenta ni siquiera con los más humildes e imprescindibles instrumentos". ${ }^{20}$ La situación generó distintas iniciativas para reunir fondos (que incluyeron rifas, bailes, donativos), además de la gestión realizada por la Secretaría de Rectoría para comprar instrumentos con un valor total de $\$ 16287$ a pagar en 30 abonos a la casa Wagner \& Levien Sucs., misma que había realizado un importante descuento en el piano Steinway de concierto y en los ocho pianos verticales Wolframm, así como en los tres armonios. ${ }^{21}$ Quién sabe cuál sería el destino final de estos instrumentos, históricos. Lo que sí sabemos es que en años recientes, alrededor del 2005, sólo quedaba un piano Wolframm de la dotación original y estaban a punto de darlo de baja por considerarlo muy usado, desconociendo su valor histórico. ${ }^{22}$

\footnotetext{
18 "Acuerdos del primer Congreso Nacional de Música”, México, 1926, AHUNAM, Fondo Escuela Nacional de Música, c. 20.

${ }^{19}$ Vid. "Un Instituto de Música", Editorial, s/f. Archivo Vertical Escuela Nacional de Música [con mayúsculas en el original].

${ }^{20}$ Vid. El Universal Gráfico, Diario ilustrado de la tarde, 2 de octubre de 1929.

${ }^{21}$ AHUNAM, Fondo Consejo Universitario, México, 19 de octubre de 1929, c. 19, exp. 135, doc. 1967, f. 1.

${ }^{22}$ El episodio fue presenciado por Ramón Mier García, miembro de nuestro Seminario de investigación, maestro de la Escuela Nacional de Música.
} 


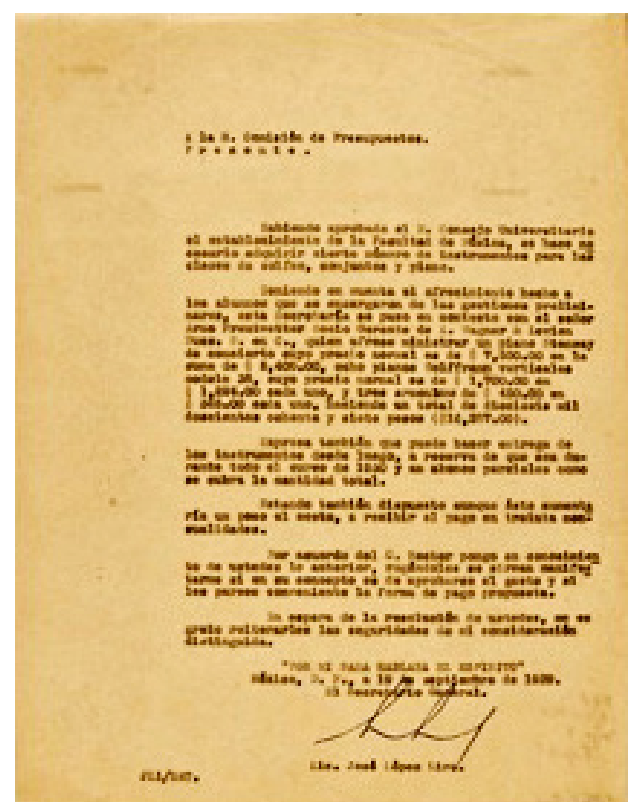

AHUNAM, Fondo Consejo Universitario, caja 19, exp. 135, doc. 1967.

Ahora bien, hacia 1979 la Escuela Nacional de Música de la UNAM se estableció en un edificio propio ubicado en el Barrio de El Carmen, Coyoacán, y quedó marcada, en ese momento, por los nombres de origen náhuatl que circulaban en distintos ambientes. Así, a su biblioteca la llamó Cuicamatini, sabio, conocedor de los cantares (León-Portilla, 2006: 380), y a dos de sus principales auditorios, Xochipilli (dios del arte, los juegos, la belleza, el baile, las flores y las canciones en la mitología azteca) y Huehuecóyotl (dios de las artes, señor de la música y de la danza ceremonial). El dato no es irrelevante: en la década de los setenta asistimos a importantes cambios en el ambiente político, cultural y social de México que, para este caso, remiten a un momento particularmente importante del movimiento indigenista que se venía fraguando desde décadas anteriores (podríamos situarlo a partir del Primer Congreso Indigenista Interamericano celebrado en Pátzcuaro, Michoacán, en 1940) en el cual la política oficial asumiera el proyecto de integrar al indígena al conjunto de la sociedad mexicana, como una vía para lograr su transformación. Fueron años en los cuales se debatió, en los suscesivos congresos indigenistas que se llevaron a cabo, la presencia de las distintas etnias en el país; la nueva antropología mexicana y la participación de los propios indígenas en los propios congresos, posicionaron un nuevo discurso que revertía el integracionismo y abogaba por la autonomía de las distintas culturas ancestrales en el seno de la sociedad mexicana (Warman et al., 1970). Indicio de la nueva visibilidad que lograba lo indígena, su valoración, en la que entraban en juego los criterios lingǘsticos, fue la presencia de nombres procedentes del náhuatl, por lo demás vinculados con el proyecto de "nación", en distintos programas e instituciones educativas y culturales.

Hasta aquí todo va muy bien, pero es precisamente en el nombre para la biblioteca del nuevo edificio, donde se trastoca la memoria: en medio de esta efervescencia, encontramos un olvido, precisamente en el nuevo nombre de la bilioteca de la Escuela, pues con ello se desconocía el que, a partir del consenso de profesores y alumnos, se le había dado inicialmente: "Gonzalo Angulo", ${ }^{23}$ quien fuera uno de sus principales hacedores.

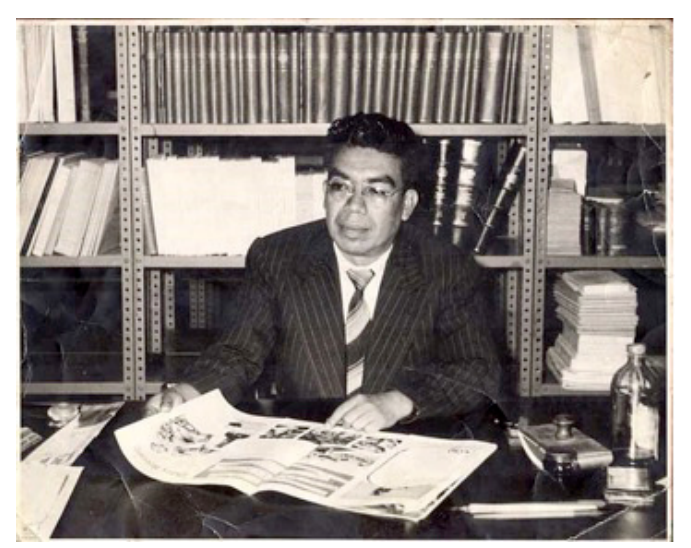

Gonzalo Angulo. Fuente: Archivo Vertical de la Facultad de Música, UNAM.

\footnotetext{
${ }^{23}$ http://cuicamatini.blogspot.mx/2014/06/historia-de-la-biblioteca-de-la-escuela.html [Consulta: noviembre del 2016].
} 
Gonzalo Angulo (1910-2005), fue quien se hizo cargo de la biblioteca en las condiciones más precarias del inicio de la Escuela. Formó el acervo inicial consiguiendo partituras por las más distintas vías, ya fuera solicitando donaciones a los profesores de la Escuela, o bien transitando las vías usuales al recorrer el mercado de la Lagunilla para comprarlas en los puestos ambulantes de los domingos, o bien en las librerías de viejo en el centro de la Ciudad de México. También se dio a la tarea de conseguir la dotación inicial de estantería y sillería, con recursos inéditos. ${ }^{24}$

No había libros en qué estudiar. Los profesores traían de Europa los libros y se los prestaban a sus alumnos. Cuando entré a la biblioteca, ni soñar en las computadoras o en las bases de datos, cómo iba yo a traer libros que no había en librerías. De casualidad, el primer lugar que visité fueron los depósitos de cartón y libros porque no había partituras en las librerías de viejo y ahí encontré cantidad de las obras de Ponce, de Elourdy [...] Le pedí dinero a los profesores para a ir a buscar entre los papeles viejos y los libros, tenía que vestirme con ropa muy usada porque salía todo embarrado de tierra, pero así logré recuperar música que no tenía ni la Casa Wagner [...] Cuando compré el primer tocadiscos los alumnos querían ir a bailar y luego no estaban acostumbrados a leer ni al préstamo de libros, sólo a jugar ajedrez y dominó (Angulo, 2005).

Angulo tenía méritos suficientes para reconocerlo en el nombre a la biblioteca de la Facultad, pero esto se borró en el nuevo edificio.

Y podríamos seguir recuperando otras historias...

No obstante los olvidos y el deseo de cancelar estas experiencias dolorosas, a la fecha el recuento de lo logrado es positivo: hoy por hoy, la Facultad de Música de la UNAM ha enriquecido las opciones para profesionalizar a los músicos.

\section{Para concluir, algunas notas sobre la memoria y la historia}

Finalmente, ¿cuáles podrían ser las aportaciones de una indagación como la que se propone referida al campo de estudios musicales?

A ojos visto, vivimos una época en la cual nuestra vida diaria, nuestras instituciones, nuestra sociedad en general, nuestra cultura social, se transforman vertiginosamente, de tal manera que nos hemos visto urgidos a buscar asideros que nos permitan comprender el presente. Uno de ello, crucial, vital, es la mirada histórica, que atraviesa el campo de las humanidades y de las ciencias sociales, en forma de 'giro memorialístico'.

Del pasado no se prescinde por el ejercicio de la decisión ni de la inteligencia; tampoco se lo convoca simplemente por un acto de la voluntad. El regreso del pasado no es siempre un momento liberador del recuerdo, sino un advenimiento, una captura del presente [...] Llegado de no se sabe dónde el recuerdo no permite que se lo desplace $[\ldots]$ insiste $[\ldots] \mathrm{El}$ pasado, para decirlo de algún modo, se hace presente [...] el tiempo propio del recuerdo es el presente [...] es el único tiempo apropiado para recordar (Sarlo, 2012: 9-10).

Si bien la memoria colectiva es un concepto que se abrió paso alrededor de los años 20 del siglo XX con la ahora clásica obra de Maurice Halbawchs, habremos de esperar a la década de los ochenta para presenciar el giro memorialístico, inicialmente dirigido a la recuperación histórica de eventos traumáticos del pasado, desconocidos o soslayados (sobrevivientes de la segunda Guerra Mundial, de los campos de

\footnotetext{
${ }^{24}$ Angulo Romero Gonzalo (s/f), "Historia de la Escuela Nacional de Música de la UNAM”, Archivo vertical de la Facultad de Música, UNAM, doc. núm. 78.
} 
exterminación de la población judía). A partir de esta perspectiva el horizonte disciplinar se amplió y enriqueció dando cabida a temáticas sugerentes que han aportado a la comprensión de lo social en la medida en que han emergido elementos sobre los modos en que individuos, grupos y comunidades procesan los recuerdos y olvidos, directamente vinculados con la construcción de imaginarios y la definición de identidades individuales y colectivas (Bresciano, 2013).

La historiografia, por su parte, también se ha volcado a hurgar en la memoria colectiva, no sólo como conocimiento del pasado por sí mismo, sino por su estrecha relación con los imaginarios que se han proyectado a la sociedad actual, mediados por la carga intergeneracional puesta en los procesos de la construcción simbólica de los espacios, de los lugares. Aquí pensamos en los lugares comunes, en las imágenes recurrentes que giran en torno al oficio de músico, a los procesos identitarios de las comunidades de arte, a las marcas institucionales que pesan sobre ellas, al impacto que han tenido las transformaciones históricas y culturales de los últimos tiempos en el hacer y pensar la música.
Más allá, y en el centro, de las aportaciones teóricas procedentes del campo de la memoria colectiva, interesa hacer una ulterior distinción entre memoria e historia, dando por descontada su estrecha vinculación: si bien la historia se apoya en su hacer en distintos registros de la memoria, ambas nociones responden a dos diversas dimensiones: la memoria remite al recuerdo/ olvido de lo vivido, donde se conjugan diferentes dosis de realidad e imaginación, en tanto que la historia nos remite a un cuerpo de saberes que responde a códigos disciplinarmente establecidos, sin que esto signifique que no se puedan flexibilizar o modificar.

Ahora bien, en las tramas de ambas dimensiones habitan las memorias históricas, así en plural, buscando el punto de convergencia de otras tantas memorias individuales, heterogéneas en su diversidad, hermanadas por la búsqueda de ese pasado común que les pertenece (Díaz Ruiz, 2010).

Ello, sin duda, abre el horizonte de comprensión de la vida de las instituciones (Díaz Ruiz, 2010) y enriquece el campo de los estudios musicales en México al visibilizar prácticas, vestigios, sentimientos, que atraviesan el campo del imaginario. 


\section{Referencias}

"Acuerdos del primer Congreso Nacional de Música" (1926), México, AHUNAM, Fondo Escuela Nacional de Música, c. 20.

Aguirre Lora, María Esther (2006), Memoria en el tiempo. La Escuela Nacional de Música de la UNAM (1929-1945 ca), México, UNAM, CESU-ENM, SOMEHIDE, Publicaciones digitales de la Dirección de Cómputo Académico de la UNAM.

Aguirre Lora, María Esther et al. (2008), Preludio y fuga. Historias trashumantes de la Escuela Nacional de Música de la UNAM (libro y disco compacto), México, UNAM (IISUEENM)/Plaza y Valdés, 2008.

Aguirre Lora, María Esther et al. (2015), Rememorar los derroteros. La impronta de la formación artística en la UNAM, México, IISUE, UNAM/Bonilla Artigas Editores.

Aguirre Lora, María Esther (2016), "Revuelo entre los músicos académicos: los primeros congresos nacionales de música (1926, 1928), en Revista Iberoamericana de Educación Superior (RIES), México, UNAM-IISUE/ Universia, vol. VII, núm. 20, <https://ries.universia. net/article/view/1814/revuelo-musicos-academicoscongresos-nacionales-musica-1926-1928> [Consulta: febrero de 2018].

Angulo Romero, Gonzalo (s/f), "Historia de la Escuela Nacional de Música de la UNAM", Archivo vertical de la Facultad de Música de la UNAM, doc. núm. 78.

Angulo Romero, Gonzalo (2005), "El resguardo de la memoria", en Abrir historias. A 75 años de la fundación de la Escuela Nacional de Música de la UNAM, México, UNAMCESU-DGAPA-ENM.

Araujo, Alejandro y Mónica Quijano (2011), "De la historización de la memoria a la historización de las experiencias del tiempo: Nora, Pomian, Hartog", en Alfonso Mendiola y Luis Vergara (coords.), Cátedra Edmundo O’Gorman. Teoría de la Historia, vol. I, México, UIA/UNAM, pp. 173-192.

Arce, Francisco et al. (1982), Historia de las profesiones en México, México, El Colegio de México/SEP.

Bresciano, Juan Andrés (coord.) (2013), La memoria histórica $y$ sus configuraciones temáticas. Una aproximación interdisciplinaria, Montevideo, Ediciones Cruz del Sur.

Chávez, Carlos (1929), "México no necesita doctores ni bachilleres en música", El Universal, 24 de julio.

Díaz Arciniega, Víctor (1989), Querella por la cultura revolucionaria (1925), México, FCE.

"Declaratoria de la UNESCO" (2010), Boletín, núm. 375, México, UNAM-Dirección General de Comunicación Social, junio [http://www.dgcs.unam.mx].

Díaz Ruiz, Pedro Luis (2010), "La memoria histórica", Revista digital Sociedad de la Información, núm. 10, Cefalea, <www.sociedaddelainformación.com/19/ memoriahistorica.pdf> [Consulta: julio de 2018].

Díaz y de Ovando, Clementina y otros (1979), La Ciudad Universitaria de México [Reseña histórica], tomo I, vol. X, México, UNAM, pp. 1929-1955.

Halbwachs, Maurice (1950), La mémoire collective, París, Presses Universitaires de France.

Herrera, Alba y María Caso (1929), "Breve historia de la fundación de la Facultad de Música por las profesoras señoritas Alba Herrera y Ogazón y María Caso", CESU, AHUNAM, Fondo Escuela Nacional de Música, caja 14, exp. 5, pp. 4928-4945.

León Portilla, Miguel (2006), La filosofia náhuatl estudiada en sus fuentes, México, UNAM-Instituto de Investigaciones Históricas.

Mejía, Estanislao (1947), Anales de la Escuela Nacional de Música, México, UNAM, 1947.

Nora, Pierre, coord. (1984), Les lieux de mémoire, I. La République, París, Gallimard.

Pomian, Krysztof (1999), "Historia cultural, historia de los semiósforos", en Jean-Pierre Rioux y Jean François Sirinelli (coords.), Para una historia cultural, México, Editorial Taurus, pp. 73-100.

Romero, C. Jesús (1947), "Bosquejo histórico de la escuela universitaria de música”, AHUNAM [IISUE], Fondo Escuela Nacional de Música, primera remesa, Jesús C. Romero, pp. 4969-4991.

"La colección Manuel M. Ponce ya es parte del programa 
Memoria del Mundo de México 2010" (2010), Boletín, núm. 375, México, UNAM-Dirección General de Comunicación Social.

Santoni Rugiu, Antonio (2011), "Sobre los conservatorios y el oficio de músico", en María Esther Aguirre, Repensar las artes. Culturas, educación y cruce de itinerarios, México, IISUE-UNAM/Plaza y Valdés, pp. 233- 259.

Sarlo, Beatriz (2012), Tiempo presente. Giro subjetivo y cultura de la memoria. Un debate, Buenos Aires, Siglo XXI.

"Versión taquigráfica de la Sesión Extraordinaria del H.

Consejo Universitario efectuada el día 23 de marzo de 1933" (1933), Archivo Histórico del Consejo Universitario, UNAM, exp. 6, año 1933, p. 76 y ss.

Warman, Arturo et al. (1970), De eso que llaman antropología mexicana, México, Editorial Nuestro Tiempo.

Zanolli Fabila, Betty María Auxiliadora (1997), "La profesionalización de la enseñanza musical en México: el Conservatorio Nacional de Música (1866-1966). $\mathrm{Su}$ historia y vinculación con el arte, la ciencia y la tecnología en el contexto nacional", tesis de doctorado en Historia, México, UNAM-FFYL, 2 vols.

\section{Cómo citar este artículo:}

Aguirre-Lora, María-Esther (2019), "Facultad de Música de la UNAM. Notas para un inventario sobre los lugares de la memoria", en Revista Iberoamericana de Educación Superior (RIES), México, UNAM-IISUE/Universia, vol. X, Núm. 29, pp. 87-103, DOI: https://doi. org/10.22201/iisue.20072872e.2019.29.524 [consulta: fecha de última consulta]. 